accidental petroleum leak occurred in an underground section near a residential area. Health risk concerns to residents from petroleum vapour were raised. An environmental site assessment (ESA) done 2011 revealed a cemented layer composed of silty and sand material from 2.0 to 4.5 metres underground, acting as 'vaportard,' limiting upward vapour migration. Impacted groundwater and soil are situated below the vapor-tard, minimising vapour intrusion. As part of the remediation, ambient and indoor vapour intrusion studies have been conducted to determine exposure risks.

Methods Community ambient levels of volatile organic compounds (VOCs) and Benzene have been measured from 2011 to 2015. In 2011, vapour intrusion (VI) study was performed to assess potential indoor air impacts from subsurface vapour intrusion. Probes were installed through concrete floor slabs and sampled for vapours.

Result $99 \%$ of VOCs and $100 \%$ of Benzene ambient air readings are below the detection limit of the photoionization device. $1 \%$ of VOC readings ranged from 0.1 to $2.0 \mathrm{ppm}$. The VI study has detected 17 VOCs in indoor and vapour samples above screening levels. These VOCs in indoor air is not likely to be related to the VI pathway, and linked to background indoor and outdoor sources related to fuel products of combustion such as vehicle traffic from a major highway, asphalt paving, and cooking fuels.

Discussion Results show the 'vaportard,' layer is effective in limiting the upward migration of vapours from the underground release area. Monitored VOCs are from ambient air pollution with mobile sources as major contributor. No risk to health of residents was identified. Remediation is on-going and has achieved the Human Health Risk Assessment targets and is in the final stage of completion.

\section{Industrial Hygiene}

\section{E-WASTE RECYCLING IN CANADA - WORKERS' EXPOSURE TO METALS AND FLAME RETARDANTS}

\footnotetext{
${ }^{1,2} \mathrm{~S} \mathrm{Gravel}^{*},{ }^{2} \mathrm{~B}$ Bakhiyi, ${ }^{3,4}{ }^{4} \mathrm{~S}$ Bernstein, ${ }^{3} \mathrm{ML}$ Diamond, ${ }^{3,4} \mathrm{LM}$ Jantunen, ${ }^{1,2} \mathrm{~J}$ Lavoie, ${ }^{3} \mathrm{~L}$ Ngyuen, ${ }^{1} \mathrm{~B}$ Roberge, ${ }^{2} \mathrm{M}-\mathrm{A}$ Verner, ${ }^{3} \mathrm{C}$ Yang, ${ }^{1,2}$ J Zayed, ${ }^{1,2} \mathrm{~F}$ Labrèche. ${ }^{1}$ Institut de recherche Robert-Sauvé en santé et en sécurité du travail, Montréal, Québec, Canada; ${ }^{2}$ Université de Montréal, Montréal, Québec, Canada; ${ }^{3}$ University of Toronto, Toronto, Ontario, Canada; ${ }^{4}$ Environment and Climate Change Canada, Egbert, Ontario, Canada
}

\subsection{6/oemed-2018-ICOHabstracts.562}

Introduction Electronic waste (E-waste) recycling is a booming industry. E-waste contains metals and flame retardants (FRs) that are released during dismantling processes, thus exposing workers. Several of these substances are associated with adverse health effects. The goal of this study is to assess occupational exposure to metals, brominated (BFR) and organophosphosphate ester (OPE) FRs in e-waste recycling facilities.

Methods Personal air sampling was performed over 8 hour work days with 10 workers in two companies. Analyses covered a dozen metals, BFRs and OPEs, including polybromodiphenyl ethers (PBDEs). Tasks and workstations were described through observation. Metals were analysed by inductively coupled plasma mass spectrometry, and flame retardants by gas chromatography and mass spectrometry. Concentrations below the limit of detection were imputed as $\mathrm{LOD} / \sqrt{ } 2$.

Results The exposure levels for metals were below occupational exposure limits. Geometric means (GM) for air concentration were $918 \mathrm{ng} / \mathrm{m}^{3}$ for copper [range: 487-2200], $346 \mathrm{ng} / \mathrm{m}^{3}$ for lead [121-1000], $85 \mathrm{ng} / \mathrm{m}^{3}$ for cadmium [60240] and one positive sample for yttrium $\left(970 \mathrm{ng} / \mathrm{m}^{3}\right)$. The highest PBDE concentration was for BDE-209 (GM=39 ng/m $\mathrm{m}^{3}$ [6-986]), and the highest OPE was tris (2-chloroethyl) phosphate (TCEP) $\left(\mathrm{GM}=156 \mathrm{ng} / \mathrm{m}^{3}[80-478]\right)$. Lead concentrations were correlated with BDE-153, BDE-183, BDE-209 and tris (1,3-dichloro-2-propyl) phosphate (TDCPP); Spearman's $\rho$ of $0.70,0.89,0.80$ and $0.71(\mathrm{p}<0.05)$, respectively. TDCPP levels were also correlated with BDE-183, copper and cadmium; Spearman's $\rho$ of $0.77,0.84$ and $0.67(\mathrm{p}<0.05)$. Highest levels of BDE-153, BDE-209, TCEP, lead and yttrium were measured at the cathode ray tubes dismantling workstation.

Conclusion These results in E-waste recycling sites clearly show concomitant exposure to various metals and flame retardants, some of which predominate in certain workstations. Upcoming additional samples and their detailed task description will help identify activities and electronic items that may require more attention in e-waste management.

\section{OCCUPATIONAL HYGIENE: STANDARDS AND PRACTICES}

Eoin Collins ${ }^{*}$. Hon. President, Occupational Hygiene Society of Ireland

\subsection{6/oemed-2018-ICOHabstracts.563}

Aim of special session The aim of the session is to show how resources provided through the REACH and CLP Regulations and the revised EN689 standard can be used as tools for assessing and controlling exposure to hazardous substances. The session also aims to share knowledge on the use of biological monitoring for exposure assessment and on how to develop a successful partnership between the fields of industrial hygiene and occupational health. Attendees will hear from experts who have developed standards, guidance and working practices in each of these areas.

${ }^{1}$ Raymond Y Vincent, ${ }^{2}$ Bridget Ginnity, ${ }^{3}$ Kate Jones, ${ }^{4}$ Michel Vangeel

${ }^{1}$ Convenor of the CEN/TC 137 WG1 (Blénod les Pont à Mousson, France)

${ }^{2}$ Ginnity Associates, Ennis, Co. Clare, Ireland

${ }^{3}$ Health and Safety Executive, Buxton, UK

${ }^{4}$ Johnson and Johnson, Antwerp, Belgium

\section{7a EN 689: THE NEW EUROPEAN STANDARD ON TESTING COMPLIANCE WITH OCCUPATIONAL EXPOSURE LIMIT VALUES}

Raymond Y Vincent.

\subsection{6/oemed-2018-ICOHabstracts.564}

(Occupational exposure limit values (OELVs) must not be exceeded over a period of time. The revision of EN 689 gives a strategy for testing compliance with OELVs by measurement of exposure by inhalation to chemical agents. The strategy describes a procedure to perform a small number of exposure measurements to demonstrate with a high degree of confidence that workers are not likely to be exposed to concentrations higher than the OELV, taking into account the variability of exposures.

It comprises three main steps concerning groups of workers having similar exposure (Similar Exposure Group-SEG). 